\title{
Smart Green Applications: From Renewable Energy Management to Intelligent Transportation Systems
}

\author{
Mario Collotta ${ }^{1, *(1)}$, Yunchuan Sun ${ }^{2}$, Luca Di Persio ${ }^{3}$, Emad Samuel Malki Ebeid ${ }^{4}$ (1) \\ and Riccardo Muradore ${ }^{3}$ \\ 1 Computers Engineering and Networks Laboratory, Faculty of Engineering and Architecture, \\ Kore University of Enna, 94100 Enna, Italy \\ 2 Business School, Beijing Normal University, Beijing 100875, China; yunch@bnu.edu.cn \\ 3 Department of Computer Science, University of Verona, 37129 Verona, Italy; luca.dipersio@univr.it (L.D.P.); \\ riccardo.muradore@univr.it (R.M.) \\ 4 University of Southern Denmark (Denmark), Campusvej 55, 5230 Odense, Denmark; esme@mmmi.sdu.dk \\ * Correspondence: mario.collotta@unikore.it; Tel.: +39-0935-536494
}

Received: 4 May 2018; Accepted: 10 May 2018; Published: 22 May 2018

\section{Introduction}

Recent years have seen an increased interest devoted to the so-called green themes, particularly with the aim to find a concrete and efficient solution to the new issues brought about by the tumultuous industrial growth of emerging economies. Researchers have responded with their studies, where several papers have been collected and the papers [1-3] have been accepted for publication. In such a scenario, the quest for Intelligent Transportation Systems, Smart Organization of human beings in Smart Cities, innovative ways to produce, handle energies and their consumption, particularly in relation to the necessity to trigger a real, green approach to the global wellness of human beings, has become an inescapable goal to focus on. These necessities have rapidly led to the Green Smart Cities Era, where Information and Communication Technology (ICT) and transport applications are merging in the new design and new planning ways of Intelligent Transportation Systems (ITS). The latter also implies innovative ICT application as well as economical managing solutions that can guarantee the energy consumption reduction of the transportation network. The overall aim is twofold: to improve traffic network efficiency and traveler experience by enhancing safety, reducing traveling time, fuel consumption and environmental impacts through gathering, organizing, analyzing, using, and sharing traffic information as well as to manage the processes of energy production with particular attention to the field of renewable energies, while aiming at the same time to a drastic reduction of the financial risk involved by handling economical instruments related to the whole of their commercial life.

Such a big deal pushes us to face extremely stimulating challenges including

- Road Transportation Support (RTS) applications based on the ideas of the Internet of Things [4], cloud computing, security [5], autonomous and self-managing transport systems [6,7], social network concepts [8], Dense Wireless Multimedia Sensor Networks [9], etc.;

- $\quad$ Real-Time ITS (RT-ITS) where efficiency [10], reliability and timeliness are the main system requirements [11-13];

- $\quad$ Energy Market Planning (EMP) where the reduction of traveling time as well as the improvement of engines efficiency, will permit drastic reductions in energy consumption [14,15];

- Management of Energy Production (MEP) viewed as an innovative as well as an effective approach to the realization of highly efficient plants to produce energy from renewable sources $[16,17]$, taking care at the same time of the optimization of the traditional ones. 
Intimately linked to this latter challenge is the implementation of virtuous economical ecosystems where ad hoc financial derivatives will be developed to help the rise of a sustainable way of life, as witnessed in [18-20].

For this reason, there is a need to disseminate, streamline, and investigate research findings coming from several different application domains.

\section{A Review of the Contributions in This Special Issue}

Several papers can be grouped under the broad heading of Energy Management in Intelligent Transportation Systems (ITS). In fact, an ITS energy management system is at the core of the optimal operation for a smart city application or in general for a transportation problem. It represents an important phase of the smart green application on the user side in order to resolve several technological and financial issues and challenges.

Ghorbani et al. [1] proposed a study about the potential of biodiesel as a diesel alternative fuel, this work was born from an assumption that diesel demand in Iran has increasingly grown due to the low price of diesel, increasing the imports. The paper showed the potential of biodiesel as a diesel alternative fuel from oil seeds and microalgae in Iran, and also analyzed government policies to reduce consumption. However, this will need fundamental strategies and policies to face and control the negative impact on the economy and the environment. Moreover, it has been proven that only 21 percent of the cultivable land of Dunaliella salina, as an indigenous green microalga isolated from the Maharlu Salt Lake, is needed to replace the diesel currently consumed in Iran with microalgal biodiesel. Finally, it was cultivated in an integration of an airlift system and a raceway pond (IARWP) to prove microalgal potentials in Iran.

Sharma et al. [2] referred to one of the key applications of ITS, which is urban surveillance, that could be improved by using the Internet of Things (IoT) paradigm. Usually, a fixed wireless infrastructure of the surveillance system is performed in ITS application. The paper introduced the use of on-demand nodes such as drones. The mobility of the drone required a new efficient communication accuracy due to the unpredictability of the wireless link. The paper described an approach that uses drones with LoRaWAN: the protocol designated for Low-Power Wide Area Networks (LPWAN). However, LoRAWAN does not avoid the formation of fail-safe, highly resilient, low-overhead, and non-redundant networks. To achieve this goal, the authors used the drone device as a LoRaWAN gateway, obtaining an energy-efficient surveillance on the energy consumption improving the localization and proposing a new communication strategy. The results showed that the suggested approach was able to conserve between $12.6 \%$ and $39.2 \%$ of the total network energy, along with an improvement in the area stress between $89.7 \%$ and $53.0 \%$, for varying numbers of drones over a fixed area.

Reddy et al. [3] described an innovative scenario where a solar-powered electric auto-rickshaw was designed and developed for the Indian urban environment. The analysis of the developed vehicle was addressed from two points of view: technical and economical. Several performance campaigns about charging and discharging were shown based on different environmental and loading conditions. Moreover, some analysis about speed vs. battery discharged was addressed to determine a good trade-off between the maximum speed reachable and power consumption. Environmental evaluations and a socio-economic analysis have been provided to give a realistic estimate of the yearly $\mathrm{CO}_{2}$ emissions and their mitigation by using the proposed technique.

Author Contributions: The authors contributed equally to this editorial.

Acknowledgments: We would like to thank all the authors for their valuable contributions to this special issue, as well as all the reviewers for their hard work, which has helped us a lot in enhancing the quality of this monograph. Moreover, we would like to express our gratitude for having been invited to act as guest editors.

Conflicts of Interest: The authors declare no conflict of interest. 


\section{References}

1. Ghorbani, A.; Rahimpour, M.R.; Ghasemi, Y.; Raeissi, S. The Biodiesel of Microalgae as a Solution for Diesel Demand in Iran. Energies 2018, 11, 950. [CrossRef]

2. Sharma, V.; You, I.; Pau, G.; Collotta, M.; Lim, J.D.; Kim, J.N. LoRaWAN-Based Energy-Efficient Surveillance by Drones for Intelligent Transportation Systems. Energies 2018, 11, 573. [CrossRef]

3. Reddy, K.S.; Aravindhan, S.; Mallick, T.K. Techno-Economic Investigation of Solar Powered Electric Auto-Rickshaw for a Sustainable Transport System. Energies 2017, 10, 754. [CrossRef]

4. Sun, Y.; Song, H. Secure and Trustworthy Transportation Cyber-Physical Systems; Springer: Berlin/Heidelberg, Germany, 2017; ISBN 978-981-10-3891-4.

5. Jacobsen, R.H.; Aliu, D.; Ebeid, E. A Low-Cost Vehicle Tracking Platform Using Secure SMS. In Proceedings of the Porto: 2nd International Conference on Internet of Things, Big Data and Security, Porto, Portugal, 24-26 April 2017.

6. Sun, Y.; Yu, X.; Bie, R.; Song, H. Discovering Time-dependent Shortest Path on Traffic Graph for Drivers towards Green Driving. J. Netw. Comput. Appl. 2017, 83, 204-212. [CrossRef]

7. Pau, G.; Campisi, T.; Canale, A.; Severino, A.; Collotta, M.; Tesoriere, G. Smart Pedestrian Crossing Management at Traffic Light Junctions through a Fuzzy-Based Approach. Future Internet 2018, 10, 15. [CrossRef]

8. Li, P.; Sun, Y.; Chen, Y.; Tian, Z. Estimating User Influence in online social Networks subject to information overload. Int. J. Mod. Phys. B 2014, 28,1-17. [CrossRef]

9. Collotta, M.; Pau, G.; Costa, D.G. A Fuzzy-based Approach for Energy-Efficient Wi-Fi Communications in Dense Wireless Multimedia Sensor Networks. Comput. Netw. 2018. [CrossRef]

10. Al-Turjman, F. QoS-aware data delivery framework for safety-inspired multimedia in integrated vehicular-IoT. Comput. Commun. 2018, 121, 33-43. [CrossRef]

11. Jacobsen, R.H.; Azar, A.G.; Ebeid, E. Design of an Event-Driven Residential Demand Response Infrastructure. In Proceedings of the 2016 Euromicro Conference on Digital System Design (DSD), Limassol, Cyprus, 31 August-2 September 2016; pp. 38-45.

12. Jacobsen, R.H.; Gabioud, D.; Basso, G.; Alet, P.J.; Azar, A.G.; Ebeid, E. SEMIAH: An Aggregator Framework for European Demand Response Programs. In Proceedings of the Euromicro Conference on Digital System Design (DSD), Madeira, Portugal, 26-28 August 2015; pp. 470-477.

13. Yu, J.; Feng, L.; Jia, L.; Gu, X.; Yu, D. A Local Energy Consumption Prediction-Based Clustering Protocol for Wireless Sensor Networks. Sensors 2014, 14, 23017-23040. [CrossRef] [PubMed]

14. Mukti, I.Y.; Prambudia, Y. Challenges in Governing the Digital Transportation Ecosystem in Jakarta: A Research Direction in Smart City Frameworks. Challenges 2018, 9, 14. [CrossRef]

15. Wang, B.; Shao, C.; Ji, X. Influencing Mechanism Analysis of Holiday Activity-Travel Patterns on Transportation Energy Consumption and Emissions in China. Energies 2017, 10, 897. [CrossRef]

16. Collotta, M.; Messineo, A.; Nicolosi, G.; Pau, G. A Self-Powered Bluetooth Network for Intelligent Traffic Light Junction Management. WSEAS Trans. Inf. Sci. Appl. 2014, 11, 12-23.

17. Kim, J.; Song, I.; Choi, W. An Electric Bus with a Battery Exchange System. Energies 2015, 8, 6806-6819. [CrossRef]

18. Fiori, C.; Ahn, K.; Rakha, H.A. Power-based electric vehicle energy consumption model: Model development and validation. Appl. Energy 2016, 168, 257-268. [CrossRef]

19. Nunes, P.; Farias, T.; Brito, M.C. Day charging electric vehicles with excess solar electricity for a sustainable energy system. Energy 2015, 80, 263-274. [CrossRef]

20. Liu, J.; Li, J.; Niu, X.; Cui, X.; Sun, Y. GreenOCR: An Energy-Efficient Optimal Clustering Routing Protocol. Comput. J. 2014, 58, 1344-1359. [CrossRef]

(C) 2018 by the authors. Licensee MDPI, Basel, Switzerland. This article is an open access article distributed under the terms and conditions of the Creative Commons Attribution (CC BY) license (http:/ / creativecommons.org/licenses/by/4.0/). 